\title{
Effect of long and short umbilical cord on perinatal outcome
}

\author{
Fahad Algreisi ${ }^{1 *}$, Richard Brown ${ }^{2}$, Alon Shrim², Samera F. Albasri ${ }^{3}$, Hanan Shamarani ${ }^{3}$, \\ Aisha AlZoubiadi ${ }^{3}$
}

\footnotetext{
${ }^{1}$ Department of Obstetrics and Gynecology, King Abdullah Medical City, Makkah, Saudi Arabia

${ }^{2}$ Department of Obstetrics and Gynecology, McGill University Health Centre, Montreal QC

${ }^{3}$ Department of Obstetrics and Gynecology, King Abdulaziz University Hospital, Makkah, Saudi Arabia
}

Received: 02 October 2016

Revised: 27 October 2016

Accepted: 02 November 2016

\author{
*Correspondence: \\ Dr. Fahad Algreisi, \\ E-mail: fahadalgreisi@yahoo.com
}

Copyright: (C) the author(s), publisher and licensee Medip Academy. This is an open-access article distributed under the terms of the Creative Commons Attribution Non-Commercial License, which permits unrestricted non-commercial use, distribution, and reproduction in any medium, provided the original work is properly cited.

\begin{abstract}
Background: Most of umbilical cords are 50 to $60 \mathrm{~cm}$ long, and very few are abnormally short or long. Short cord is defined as $<35 \mathrm{~cm}$ and long cord $>80 \mathrm{~cm}$. Short cords maybe associated with adverse perinatal outcomes such as IUGR, congenital malformation, intrapartum distress and 2 fold. Cord length is influenced positively by both the volume of amniotic fluid and fetal mobility. Objective was to determine the association between abnormal umbilical cord length and perinatal outcome.

Methods: A retrospective cohort study, conducted at McGill University, using the computerized MOND database. All Term singleton deliveries between 2001 and 2007 were included. We based our population according to the length of the umbilical cord following delivery: Normal cord length (measured length $35-80 \mathrm{~cm})$, short cord $(<35 \mathrm{~cm})$ and long cord $(>80 \mathrm{~cm})$. Admission to the Neonatal Intensive Care Unit (NICU) was compared to the normal cord group. Results: Of the 14,873 deliveries included, 13518 (90.9\%) had normal cord lengths, 980 (6.6\%) had short cords, and $375(2.5 \%)$ long cords. Maternal age, gravidity, birth weights, and rate of male gender babies were all increased in the long cord group and decreased in the short cord group (all $\mathrm{p}<0.05$ ). NICU admissions were more common in the short cord group (OR 1.9; 95\%, CI 1.4-2.6) but not in the long cord group. Babies in both the short and long cord groups had higher rates of Apgar score <7 (OR 1.3, 95\% CI 1.1-1.7 and OR 1.7, 95\% CI 1.2-2.3, respectively) with no significant difference in cord $\mathrm{pH}$. Gravidity and abnormal cord length were independent predictors of NICU admission.
\end{abstract}

Conclusions: Short umbilical cord is associated with higher rates of NICU admissions and low Apgar scores.

Keywords: Long umbilical cord, Perinatal outcome, Short umbilical cord, Umbilical cord

\section{INTRODUCTION}

Most umbilical cords are 50 to $60 \mathrm{~cm}$ in length, and very few are abnormally short or long. A short cord is $<35 \mathrm{~cm}$ and a long cord is $>80 \mathrm{~cm}^{1}$ A short cord maybe associated with adverse perinatal outcomes, such as intrauterine growth retardation (IUGR), congenital malformation, and intrapartum distress. ${ }^{1}$
Cord length is influenced positively by both the volume of amniotic fluid and foetal mobility. Miller et al, reported an association between short cord and chronic oligohydramnios and decreased fetal movement. ${ }^{2}$ Umbilical cord diameter is also an important foetal marker. Lean umbilical cords have been associated with poor foetal growth and large diameter cords with macrosomia, although the clinical utility of this parameter is still unclear. ${ }^{3-5}$ 
In 1981, Rayburn et al, reported an association between cord length and perinatal outcome. ${ }^{6}$ Berg et al reported that an abnormally short or long umbilical cord by itself was associated with an increased risk of acid-base imbalance at delivery and does not require routine cord blood gas determination. ${ }^{1}$ Atalla et al, did not find any relationship between umbilical cord indices and intrapartum foetal heart rate (FHR) decelerations, meconium staining of the amniotic fluid, or mode of delivery. $^{7}$

The objective of this study was to investigate the association between umbilical cord length and pregnancy outcome.

\section{METHODS}

This was a retrospective cohort study in which we used the MOND (McGill Obstetrics and Neonatal Database) system as our database. The MOND is a computerised hospital and neonatal database that was created in 1978. Data is coded soon after discharge for all deliveries and infants born at McGill University in Montreal, Canada. Maternal and infant charts are coded after discharge by a clerk for routine entries and by three professionals (nurse, obstetrician and neonatologist) for items requiring judgmental decisions. All term singleton deliveries from 2001 until 2007 were included.

We categorised our sample based on the length of the umbilical cord at the time of delivery. After reviewing data from the literature, we categorized umbilical cord length into normal, short and long. Umbilical cord: group A: normal length varied from 35 to $80 \mathrm{~cm}$. Group B: Cords $<35 \mathrm{~cm}$ were categorized as short. Group C: $>80$ $\mathrm{cm}$ were long. Our inclusion criteria were all term (3-42 weeks) singleton deliveries, either vaginal deliveries (normal or instrumental) or emergency caesarean section (C/S) due to failure to progress or foetal intolerance (distress) during labor. Our exclusion criteria were as follows:

\section{- Twin pregnancy}

- $\quad$ Elective CS

- Preterm deliveries

- Breech and placenta previa

- Gravidity $>10$

We studied the effect of the umbilical cord on the following variables: maternal age, gravidity, parity, gestational age, birth weight, gestational diabetes mellitus (GDM), gestational hypertension (GHTN), cord PH <7, Apgar score $<7$ at 1 minute, gender of the fetus, neonatal intensive care unit (NICU) admission, maternal smoking, instrumental delivery, CS rate, duration of the second stage of labor, placental weight, single umbilical artery, velamentous cord insertion, cord prolapse, Postpartum Hemorraghe (PPH) meconium, Congenital anomalies, Respiratory distress syndrome (RDS) and foetal death.

\section{Statistical analysis}

Continuous variables are described as means and standard deviations and categorical variables are expressed as absolute numbers and percentages. Dichotomous variables were analyzed using the chisquare and Fisher's test. A P-value <0.05 (two-sided) was considered to indicate statistical significance.

\section{RESULTS}

During the study period, 20057 women delivered at the McGill University Health Center. Of these, 14968 patients fulfilled the inclusion criteria. Based on our categorization, 13602 patients had normal cord lengths, 987 had short cords, and 379 had long cords.

The average maternal age at delivery was similar in all three groups (31.9 years). Gravidity and parity were also similar in all groups, with a value of 2 and 1 , respectively (Table 1). Gestational age was approximately 40 weeks in all groups. On the other hand, birth weight and placental weight were highest in the long cord group (3645g and 835.1g, respectively).

Table 1: Demographic data.

\begin{tabular}{|llll|}
\hline & $\begin{array}{l}\text { Long cord } \\
\text { N=379 }\end{array}$ & $\begin{array}{l}\text { Short cord } \\
\text { N=987 }\end{array}$ & $\begin{array}{l}\text { Normal cord } \\
\text { N=13602 }\end{array}$ \\
\hline $\begin{array}{l}\text { Maternal } \\
\text { age }\end{array}$ & $32+/-5.25$ & $31+/-5.17$ & $32+/-5.01$ \\
\hline gravidity & $2+/-1.71$ & $2+/-1.68$ & $2+/-1.65$ \\
\hline parity & $1+/-1.23$ & $1+/-1.38$ & $1+/-1.14$ \\
\hline $\begin{array}{l}\text { Birth } \\
\text { weight }\end{array}$ & $3645 \mathrm{~g}+/-$ & $3332 \mathrm{~g}+/-$ & $3465+/-$ \\
\hline $\begin{array}{l}\text { Gestational } \\
\text { age }\end{array}$ & $40 \mathrm{wks}+/-$ & $40 \mathrm{wks}+/-$ & $40 \mathrm{wks}+/-$ \\
\hline $\begin{array}{l}\text { Duration } \\
\text { of 2 }\end{array}$ & 1.13 & 1.21 & 1.16 \\
\hline $\begin{array}{l}\text { Placenta } \\
\text { weight }\end{array}$ & $7.84+/-$ & $1.42+/-$ & $9.27+/-$ \\
\hline
\end{tabular}

Further analysis revealed that the proportion of male infants was significantly higher in the long cord group $(\mathrm{P}=0.0002)$ contrary to the short cord group, which had a higher proportion of female infants $(\mathrm{P}<0.0001)$. Maternal smoking was found to has statistically significant risk of short cord $(\mathrm{P}=0.0002)$. Gestational diabetes mellitus was more frequent in the long cord group $(\mathrm{P}=0.03)$. The incidence of gestational hypertension was not significantly different among the three groups.

The umbilical cord $\mathrm{pH}<7.0$ at delivery was significantly higher in short cord group with $\mathrm{P}<0.0001$. Apgar score $<7$ at one minute was statistically significant in long and short cord group more the Normal cord group (P $<0.0001)$. 
The use of instrumental delivery did not differ between the groups. However, the CS rate was higher in both short cord group $\mathrm{P}<0.0001$ and long cord group compare to normal cord group $\mathrm{P}=0.04$. We found that $\mathrm{NICU}$ admission was more in short cord group with $\mathrm{P}$ $<0.0001$ compare to other groups.

The groups did not differ in terms of the incidence of congenital anomalies. Respiratory distress syndrome was similar in all groups but foetal death was more in short cord group with $(\mathrm{P}=0.0002)$ in comparison to normal and long cord groups.
The rate of single umbilical artery was higher and statistically significant in long cord group $\mathrm{P}<0.0001$ compare to other groups. Velamentous insertion of cord was higher in long cord group $(\mathrm{P}=0.004)$. Cord prolapse was significantly lower in the short cord group compared with the normal and long cord groups $(\mathrm{P}=0.04)$. Meconium was more with long cord $(\mathrm{P}=0.001)$. The incidence of PPH did not differ between all groups $(\mathrm{P}=$ $0.5)$.

Table 2: Umbilical cord length and perinatal outcome.

\begin{tabular}{|lllllllll|}
\hline & $\begin{array}{l}\text { Long cord } \\
\text { (n:379) }\end{array}$ & $\%$ & $\mathrm{P}$ value & $\begin{array}{l}\text { Short cord } \\
(\mathrm{n}: 987)\end{array}$ & $\%$ & $\mathrm{P}$ value & $\begin{array}{c}\text { Normal cord } \\
\text { (n:13602) }\end{array}$ & $\%$ \\
\hline NICU & 14 & $3.69 \%$ & $\mathrm{P}=0.07$ & 59 & $5.98 \%$ & $\mathrm{P}<0.0001$ & 311 & $2.29 \%$ \\
\hline A/S ${ }^{1}<7 @ 1 \mathrm{MIN}$ & 57 & $15.04 \%$ & $\mathrm{P}<0.0001$ & 123 & $12.46 \%$ & $\mathrm{P}<0.0001$ & 1071 & $7.87 \%$ \\
\hline Smoking & 22 & $5.80 \%$ & $\mathrm{P}>0.5$ & 90 & $9.12 \%$ & $\mathrm{P}=0.0002$ & 856 & $6.29 \%$ \\
\hline INST DEL & 28 & $7.39 \%$ & $\mathrm{P}>0.5$ & 76 & $7.70 \%$ & $\mathrm{P}>0.5$ & 1012 & $7.44 \%$ \\
\hline C/S RATE & 33 & $8.71 \%$ & $\mathrm{P}=0.04$ & 216 & $21.88 \%$ & $\mathrm{P}<0.0001$ & 1663 & $12.23 \%$ \\
\hline PH<7.0 & 4 & $1.06 \%$ & $\mathrm{P}=0.12$ & 3 & $0.30 \%$ & $\mathrm{P}=0.4$ & 66 & $0.49 \%$ \\
\hline GDM & 30 & $5.54 \%$ & $\mathrm{P}=0.03$ & 54 & $5.47 \%$ & $\mathrm{P}>0.5$ & 724 & $5.32 \%$ \\
\hline HTN & 21 & $5.54 \%$ & $\mathrm{P}=0.4$ & 39 & $3.95 \%$ & $\mathrm{P}=0.5$ & 623 & $4.58 \%$ \\
\hline Anomalies & 28 & $7 \%$ & $\mathrm{P}=0.5$ & 78 & $8 \%$ & $\mathrm{P}=0.12$ & 897 & $7 \%$ \\
\hline RDS & 0 & $0 \%$ & $\mathrm{P}=0.64$ & 1 & $0.10 \%$ & $\mathrm{P}=0.5$ & 16 & $0.12 \%$ \\
\hline IUFD & 1 & $0.25 \%$ & $\mathrm{P}=0.25$ & 5 & $0.50 \%$ & $\mathrm{P}=0.0002$ & 12 & $0.09 \%$ \\
\hline Single artery & 8 & $2 \%$ & $\mathrm{P}<0.0001$ & 6 & $1 \%$ & $\mathrm{P}=0.3$ & 53 & $0.39 \%$ \\
\hline VELM & 13 & $3 \%$ & $\mathrm{P}=0.0004$ & 14 & $1 \%$ & $\mathrm{P}>0.5$ & 209 & $2 \%$ \\
\hline Prolapse & 1 & $0.26 \%$ & $\mathrm{P}>0.5$ & 0 & $0 \%$ & $\mathrm{P}=0.04$ & 56 & $0.41 \%$ \\
\hline PPH & 8 & $2 \%$ & $\mathrm{P}>0.5$ & 15 & $2 \%$ & $\mathrm{P}=0.5$ & 250 & $2 \%$ \\
\hline Meconium & 50 & $13 \%$ & $\mathrm{P}=0.001$ & 80 & $8 \%$ & $\mathrm{P}>0.5$ & 1142 & $8 \%$ \\
\hline
\end{tabular}

$\mathrm{A} / \mathrm{S}^{1}$ - Apgar score ${ }^{1}$, INST DEL ${ }^{2}$ - Instrumental delivery ${ }^{2}$, VELM $^{3}$ - Velamentous insertion of umbilical cord ${ }^{3}$

\section{DISCUSSION}

We found that a shorter cord was associated with an increased rate of CS and NICU admission. Factors such as sex of the fetus, maternal smoking, and gestational diabetes were also associated with umbilical cord length. Of note, we found a significant difference between genders, with male babies having longer cords and females having shorter cords, which is consistent with the findings of other authors. ${ }^{8,10}$ Our finding that maternal smoking was associated with short cords conflicts those of other investigators, although it has been reported that maternal smoking was related to intrauterine growth restriction. ${ }^{8}$ Furthermore, neonates born to mothers with GDM had significantly long cords, a finding that was expected, as hyperglycemia due to GDM is a welldocumented significant risk factor for fetal macrosomia.

In general, our results are in line those of other authors who investigated the relationship between umbilical cord length and pregnancy outcomes. ${ }^{8}$ In a previous retrospective analysis of data from the Japan Society of
Obstetrics and Gynecology Successive Pregnancy Birth Registry System, investigators found that the rate of unplanned CS was increased in neonates born with short cords. ${ }^{11}$ Conversely, other authors have reported the rate of CS to be increased in neonates born with long cords. ${ }^{11}$ For example; Weiner et al reported that the rate of CS was higher among neonates with short cords. ${ }^{12}$ In another study, it was found that the rate of CS was decreased by $50 \%$ in infants with short cords. ${ }^{8}$ Nevertheless, we expect differences between our findings and those of other authors, as the measurement of cord length varied in these studies. In the study conducted by Krakowiak et al., for example, the authors used the International Classification of Disease codes to identify and classify short cords. ${ }^{8}$ Thus, it might not be possible for us to make relevant comparisons. Besides, the indications for CS cannot be overlooked, as these probably contribute to the differences in results observed among reports.

Notably, our results proposed an association of acidaemia and birth asphyxia (Apgar $<7$ at one minute) with short cords. However, contrary to our report, Atalla RK did not 
find a relationship between the acid-base balance of the umbilical artery and umbilical cord length. ${ }^{7}$ Other factors such as small-for-gestational-age deliveries, nonreassuring fetal status, hypoxic encephalopathy, and infant mortality have been associated with short cords, suggesting that close monitoring should be offered in newborns with short cords. Unfortunately, we did not explore the effect of these factors in our study.

Our analyses are subject to limitations related to the study design. We included deliveries from the database of an academic hospital in Montreal, Canada, and the data may be prone to selection bias. It may this be necessary to conduct a larger scale, population-based study to study the relationship between cord length and fetal outcome.

\section{CONCLUSION}

Most of the umbilical cords are within normal length range, yet if the umbilical cord is abnormally long or short, this might be a considerable explanation of abnormal outcome in absence of obvious cause of the unexpected outcome. This conclusion cannot be generalized as we still in need of multicenter populationbased studies to investigate the reliability of the umbilical cord length on the fetal outcome.

Funding: No funding sources Conflict of interest: None declared

Ethical approval: The study was approved by the Institutional Ethics Committee

\section{REFERENCES}

1. Berg TG, Rayburn WF. Umbilical cord length and acid-base balance at delivery. J Reprod Med 1995;40(1):9-12.

2. Miller ME, Higginbottom M. Short umbilical cord: its origin and relevance. Pediatrics. 1981;67(5):61862.

3. Raio L, Ghezzi F, Di Naro E. Sonographic measurement of the umbilical cord and fetal anthropometric parameters. Eur J Obstet Gynecol Reprod Biol. 1999;83:131.

4. Cromi A, Ghezzi F, Di Naro E. Large cross-sectional area of the umbilical cord as a predictor of fetal macrosomia. Ultrasound Obstet Gynecol. 2007;30:804

5. Barbieri C, Cecatti JG. Validation study of the capacity of the reference curves of ultrasonographic measurements of the umbilical cord to identify deviations in estimated fetal weight. Acta Obstet Gynecol Scand. 2008;87(3):286-91.

6. Rayburn WF, Beynen A. Umbilical cord length and intrapartum complications. Obstet Gynecol 1981;57(4):450-2.

7. Atalla RK, Abrams K. Newborn acid-base status and umbilical cord morphology. Obstet Gynecol. 1998;92(5):865-8.

8. Krakowiak P, Smith EN. Risk factors and outcomes associated with a short umbilical cord. Obstet Gynecol. 2004;103(1):119-27.

9. Naeye RL. Umbilical cord length: clinical significance. J Pediatr. 1985;107(2):278-81.

10. Misra DP, Salafia CM, Miller RK, Charles AK. Nonlinear and gender-specific relationships among placental growth measures and the fetoplacental weight ratio. Placenta. 2009;30(12):1052e7.

11. Yamamoto Y, Aoki S, Oba MS, Seki K, Hirahara F. Relationship between Short Umbilical Cord Length and Adverse Pregnancy Outcomes. Fetal Pediatr Pathol. 2016;35(2):81-7.

12. Weiner E, Fainstein N, Schreiber L, Sagiv R, Bar J, Kovo M. The association between umbilical cord abnormalities and the development of non-reassuring fetal heart rate leading to emergent cesarean deliveries. J Perinatol. 2015 Nov;35(11):919-23.

Cite this article as: Algreisi F, Brown R, Shrim A, Albasri SF, Shamarani H, AlZoubiadi A. Effect of long and short umbilical cord on perinatal outcome. Int J Reprod Contracept Obstet Gynecol 2016;5:4228-31. 